\title{
Shaking loose the ropes
}

The Reason I Jump: The Inner Voice of a Thirteen-Year-Old Boy with Autism Naoki Higashida (author), KA Yoshida and David Mitchell (translators)

Random House; 2013

$T$ The Reason I Jump: it's a curious title for a book. Why does Naoki Higashida, a 13-year-old boy with autism, jump? "When I'm jumping, I can feel my body parts really well, too - my bounding legs and my clapping hands - and that makes me feel so, so good." Later he adds: "So by jumping up and down, it's as if I'm shaking loose the ropes that are tying up my body."

The book gathers up Naoki's answers to 58 questions about why children with autism behave the way they do. In addition to elucidating the inner life of an autistic child, Naoki's book expresses his desire for connection. He recounts his thoughts, feelings and behaviour in the hope of chipping away at the barriers of misunderstanding between individuals with autism and the people in their lives who struggle to know and love them.

There is much about autism and autism spectrum disorder that we don't understand. Why are more and more children, especially boys, receiving diagnoses of autism? A few years ago, sociologist Gil Eyal explained the contemporary "autism epidemic" in The Autistic Matrix. The term "spectrum disorder" implies mixed causality, a range of presentations and challenges in accurate diagnosis and effective treatment. Evdokia Anagnostou and colleagues, in a recent review of autism spectrum disorder, begin by saying that it, "encompasses wide variation in symptom severity and functional impact"(CMAJ 2014;186:509-19).

Naoki is not the first person with autism to write about his experiences, but he is one of the youngest. We don't know where on "the spectrum" he sits. Nevertheless, for would-be authors, it's an inspiring story of how some books are written against great odds. The provenance of the book reminds me of The

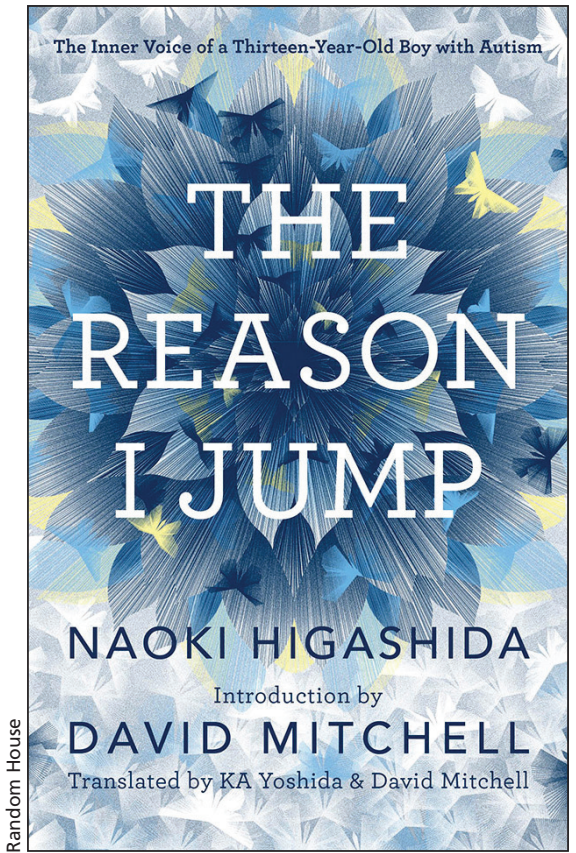

Diving Bell and the Butterfly by JeanDominique Bauby - another person lacking the usual means of self-expression. In the face of such impressive obstacles, it takes a team to make a book.

In Naoki's case, that team included his mother and a teacher who designed a special alphabet grid of 40 Japanese hiragana letters for him when he was still in primary school. With the help of a transcriptionist, he began writing by pointing to characters on the grid to spell words and eventually compose sentences. It's a painstaking way to put words on a page. Naoki combines perseverance with insight: "What kept me hammering away at it was the thought that to live my life as a human being, nothing is more important than being able to express myself."

The team for the 2013 English translation of the original 2006 edition includes author David Mitchell and his wife KA Yoshida, who have two children, one of them autistic. According to Mitchell in his introduction, the text "offers up proof that locked inside the helpless-seeming autistic body is a mind as curious, subtle and complex as yours, as mine, as anyone's." It would take a bilingual reader to determine how faithfully the teenager's Japanese text has been rendered in English.

In Naoki's answers to questions 14, "Why do you ignore us when we're talking to you?" and 16, "Is it true that you hate being touched?" he speaks directly about the nature of sentience: "Simply put, people with autism never, ever feel at ease, wherever we are."

Although he may never feel at ease, he shares with the reader his "pleasure in one thing that you probably won't be able to guess. Namely, making friends with nature. ... [N]ature is always there at hand to wrap us up, gently: glowing, swaying, bubbling, rustling."

In a conversational prose style tempered with modesty and wit, Naoki describes his unusual sensory, affective and behavioural realities. In addition to what he calls "tactile issues," he articulates aspects of his visual and auditory perceptions, memory and self-regulation of attention, speech and movement. He takes us "behind the scenes" of many behaviours that people without autism often find puzzling or disturbing.

Naoki's answers reveal an empathic spirit that I don't usually associate with teenage boys. He says that for those with autism, "[t]he hardest ordeal for us is the idea that we are causing grief for other people ... that our lives are the source of other people's unhappiness."

Naoki paints a startling picture of the richness and the "hardships" that define the inner life of a young person with autism. This new knowledge is a benefit for the reader, but maybe not the best reason to read the book. The greater success of this young writer's work, and one not likely to be documented, will depend on the reader's response to the writer's plea. He repeats it several times: "Please never give up on us. ... Please, keep battling alongside us."

\section{Vincent Hanlon MA MD}

Physician and Family Support Program Alberta Medical Association

Calgary, Alta.

CMAJ 2015. DOI:10.1503/cmaj.131761 